\title{
De un continente al otro: el desaparecido transnacional, la cultura humanitaria y las víctimas totales en tiempos de guerra global
}

\section{From one Continent to another: the Transnational Disappeared, the Humanitarian Culture and the Total Victims in Global War Times}

\author{
Gabriel GatTI \\ Centro de Estudios sobre la Identidad Colectiva (CEIC) \\ Departamento de sociología 2 \\ Universidad del País Vasco/Euskal Herriko Unibertsitatea \\ g.gatti@ehu.es
}

Recibido: 10.11 .2010

Aprobado definitivamente: 03.06.2011

\section{RESUMEN}

En España, en los últimos años, se ha instalado en el debate público, en la práctica de los movimientos pro-derechos humanos y, en menor medida, en la acción legislativa, una figura hasta hace poco foránea, el detenido-desaparecido. Prolongando los resultados derivados de una investigación sobre los universos sociales del detenido-desaparecido desarrollada en Argentina y Uruguay entre 2005 y 2008 , este texto indaga en las particularidades del viaje del desaparecido desde el sur de América Latina hasta la Península Ibérica. El artículo, sin discutir la inadecuación o no entre el caso español y la definición que el derecho humanitario internacional ha construido del detenido-desaparecido, analiza el "éxito", español y planetario, de esta figura con arreglo a tres referencias (el mundo humanitario, la justicia transicional y el derecho humanitario internacional, la idea de víctima) y a un contexto (la "guerra global contra el terrorismo"). Con unas y otro, es la hipótesis, se explica la ascensión del desaparecido a puestos de privilegio en la "jerarquía de la desdicha", la que ordena a las víctimas totales y universales.

Palabras Clave: Detenidos-desaparecidos, víctimas, cultura humanitaria, derechos humanos

\begin{abstract}
In recent years, in Spain, the detained-disappeared figure has been incorporated in public debate, in the experience of pro-human rights movements and, to a lesser degree, in the legislative practice. Extending the findings derived from a research on the social universes of the detained-disappeared that took place in Argentina and Uruguay from 2005 to 2008, this text investigates the peculiarities of the disappeared's journey from the South of Latin America to the Iberian Peninsula. Without discussing whether the inadequacy or not between the Spanish case and the international humanitarian justice definition constructed about the detained-disappeared, this paper explores the Spanish and global "success" of this figure in relation to three references (the humanitarian world, the transitional justice and the humanitarian international Wright, and
\end{abstract}


the idea of victim) and a context (the "global war against terrorism"). Using the formers and the latter, that is the hypothesis, it is explained the ascension of the disappeared to the highest positions in the "hierarchy of despair", the one that organizes the global and total victims

KEYwords: Detained-disappeared, Victimhood, Humanitarian Culture, Human Rights

\section{SUMARIO}

1. 114.000. 2. El desaparecido transnacional. Marcos de guerra y cultura humanitaria. 3. El desaparecido modélico. Las estructuras de sentido que la desaparición forzada de personas moviliza (y despedaza). 4. El desaparecido inmutable. Cabalgando por el mundo a lomos del derecho humanitario. 5. A modo de cierre: algunas consecuencias (no intencionadas) de la transnacionalizacion del detenido-desaparecido. 


\section{114.000}

Terminando el verano de 2010, coincidiendo con el Día Internacional del detenido-desaparecido, una nota de prensa de la oficina española de Amnistía Internacional circula por las perezosas rotativas agostizas y se convierte en noticia de titulares con tipos de gran tamaño: ciento catorce mil familias "siguen buscando a sus desaparecidos durante la Guerra Civil española". Desde El Mundo a El PAís, a un lado y otro del espectro político, se da cuenta de la que bien entrado el 2010 es todavía noticia de actualidad: que en España habría desde los años '40 más de cien mil personas que merecen un adjetivo extraño para definir su actual estatuto vital, detenidos-desaparecidos.

La nota, aprovechando lo que la fecha conmemora, amplia la noticia y equipara lo que aún sucede en España - miles de casos de desapariciones forzadas no resueltas - con otras situaciones similares en el mundo: 25 gobiernos denunciados por desaparición forzada de personas en 2009, millares de detenidosdesaparecidos producto de guerras recientes $(12.000$ denuncias en Bosnia Herzegovina, 16.409 en Irak, 179 en Ingusetia, 1.300 en Nepal, 2.270 en El Salvador...). La nota, en fin, se cierra explicando qué es la desaparición forzada de personas - "La desaparición forzada es una grave violación de derechos humanos cometida por los Estados..."-, ${ }^{1}$ a qué afecta - "una persona detenida en secreto, torturada, asesinada..."-, cuáles son algunas de las particularidades del horror que genera - "una familia que sufre años o décadas bajo el peso de estos crímenes gubernamentales (...). No saben si están vivos o muertos, si han sido encarcelados, torturados, mantenidos en condiciones inhumanas o enterrados en una fosa común. No saben si algún día aparecerán, ni en qué condiciones"- y quién legitima esta definición, el derecho internacional a través de la Convención Internacional para la Protección de Todas las Personas contra las Desapariciones Forzadas.

Estados, individuos, organismos humanitarios, vivos murientes, muertos vivientes... comparecen a un tablero, el de la desaparición forzada de personas, en el que España había esquivado jugar hasta hace bien poco. Así, un viejo problema español se ve, de repente, incluido en una categoría universal, nueva para él, categoría que lo subsume, que lo explica. El problema, antes sin nombre (o sin nombre consensuado), da al fin con el suyo: los "114.000" son parte de un objeto cuya existencia sanciona el derecho universal, víctimas de un delito - la desaparición forzada de personas- sobre el que trabajan numerosas agencias humanitarias, casos de una figura - el detenido-desaparecido-, alrededor de la que pivota en todo el mundo la vida de cientos de colectivos de víctimas, movilizadas a veces, sufrientes y silenciosas las más, en países distintos, en épocas distintas. También, parece, en España.

La nota de prensa de Amnistía Internacional es pues más relevante de lo que parece: anuncia que la desaparición forzada y los desaparecidos han sorteado al fin las dificultades que encontraban al intentar pasar la frontera española y que ya se mueven con comodidad a un lado y otro del Atlántico - desde la Alemania nazi hasta Guatemala, desde Argentina hasta Ingusetia, desde Guantánamo hasta Nepal-, que viajan también cómodos de una época a otra de la posguerra mundial a la Guerra Civil española, de las dictaduras latinoamericanas de los '70 a las guerras del post-comunismo-. Impasible, el detenido-desaparecido surca espacios y tiempos; sancionado por las leyes internacionales, se ha convertido en un objeto rocoso: siempre igual por mucho que se desplace, sin inmutarse a pesar de las diferencias evidentes entre sus distintos usos locales.

Y sin embargo, la desaparición y el detenido-desaparecido son una estrategia represiva y una figura que, a poco que se establezca una genealogía rigurosa, no resulta fácil de pensar sin tener en cuenta algunas características sociohistóricas del contexto en el que nació, si no el hecho, sí el nombre, esto es, allá en los '70 y en Argentina. Es cierto que estrategias represivas similares las hubo antes (en Argelia, en Alemania, en Vietnam, en Egipto...); lo es también que el dispositivo desaparecedor (Calveiro, 1998) y la figura del detenido-desaparecido son ahora, de la mano del derecho universal humanitario, entidades internacionalizadas; es verdad también que para definirlas, pensarlas, casi nunca sancionarlas, se com-

\footnotetext{
${ }^{1}$ Leído el 30 de agosto en El Mundo (http://www.elmundo.es), que toma la nota del sitio Web de Amnistía Internacional (cf. http:// www.es.amnesty.org/noticias/noticias/articulo/decenas-de-miles-de-personas-siguen-desaparecidas-en-el-mundo-por-motivos-politicos/, acceso el 13 de octubre de 2010.
} 
parten universalmente nombre, argumentos, lógica de la prueba... Pero es de igual modo innegable que, aplicado al caso español, es cosa bien reciente que los antes llamados fusilados paseados sean ahora nombrados, pensados, reivindicados como detenidos-desaparecidos. Evidentemente, en el camino algo ha debido pasar.

Reconstruir qué ha pasado para que se diese este movimiento de transnacionalización primero y de apropiación local después de un delito de lesa humanidad, la desaparición forzada de personas, y de una figura, la del detenido-desaparecido es el objetivo de este texto. No lo es revelar el verdadero contenido del concepto de detenido-desaparecido ni tampoco denunciar lo mal o bien que se utiliza la figura en el campo de los derechos humanos y de la memoria que se está constituyendo en los últimos años en España. ${ }^{2}$ Así, el de este trabajo es un interés casi arqueológico: determinar cuáles son las capas o formaciones discursivas con arreglo a las que se explica el desembarco, y con éxito, de esta figura en España. Tras dedicar unos párrafos al contexto en el que fermenta la figura del desaparecido transnacional, indicaré cuáles son a mi juicio las claves que definen al desaparecido modélico, el que se produjo en el Cono Sur latinoamericano en los '70, para luego centrarme en las características del desaparecido inmutable, aquel cuyas características fija el derecho humanitario internacional. Como cierre comentaré algunas de las consecuencias que tiene o puede tener el proceso de transnacionalización de la figura del detenido-desaparecido. Una doble conjetura atraviesa el desarrollo de ese argumento: que el detenido-desaparecido es una de las expresiones más complejas, integrales y apoteósicas de la figura de la víctima, protagonista de la internacionalmente creciente (y expansiva) cultura humanitaria; que el éxito de la figura del detenido-desaparecido y el hallazgo por doquier de situaciones que parecerían responder a lo que el derecho dice que es un desaparecido repercute tanto en el reconocimiento y la visibilidad de víctimas que nunca fueron lloradas como en la reducción a sus aspectos más visibles y evidentes de situaciones de enorme complejidad histórica y sociológica.

\section{ELDESAPARECIDOTRANSNACIONAL. MARCOS DE GUERRA Y CULTURA HUMANITARIA}

En Mala gente que camina (2006) Benjamín Pra$\mathrm{do}^{3}$ trama una historia que juega en un terreno muy poco recorrido por la literatura española, el del destino de los hijos de represaliados por el franquismo durante la Guerra Civil y, sobre todo, la posguerra española que fueron dados en adopción a familias afines al régimen. En la historia, conmovedora, juegan no pocos de los protagonistas habituales en este género, ${ }^{4}$ tanto entre la lista de los protagonistas de consistencia difusa - la culpa, el secreto, la venganza, la ocultación, la traición, el odio, la humillación, el despecho, el reproche...- como en la de los más concretos y humanos. Uno de estos es Juan Urbano, actor principal de esta historia, profesor de instituto e investigador, que prepara una ponencia sobre Dolores Serna, autora en los ' 40 de una novela, Óxido, hoy olvidada. Otro es un secundario, Marconi Santos. Es la presencia de Santos en la novela la que me llama la atención: dueño y animador de un restaurante, el "Montevideo", donde el protagonista come y desayuna a diario, Santos es un exiliado uruguayo de la dictadura de los '70; cumple un rol crucial en la trama que urde Prado, pues a medida que Juan Urbano profundiza en su investigación y encuentra tras la historia de Dolores Serna una verdad sórdida, en la que desaparición forzada o niños apropiados son parte de los ingredientes, Marconi Santos cuenta qué

\footnotetext{
${ }^{2}$ Tarea en la que sí se han visto comprometidos algunos intelectuales y periodistas que habitualmente ocupan las primera filas de la escena pública española, caso, entre muchos otros, de Javier Pradera (2008) o Reyes Mate (2009). Sobre las singularidades del debate público español en relación a la cuestión de la memoria, cf. en este mismo número de Política y Sociedad Faber, Sánchez León, Izquierdo, 2011.

${ }^{3}$ Agradezco a Daniel Feierstein que en alguna conversación sobre el tratamiento de la figura del detenido-desaparecido en la literatura y el cine me haya recomendado la lectura de esta novela, entre otras que permiten pensar la "emigración" del desaparecido de Argentina a España.

${ }^{4}$ Que quizás no sea todavía "género" de este lado del Atlántico, aunque empieza a convertirse en tal (véase sino la profusa y ancha obra de Almudena Grandes o algunos trabajos de Javier Cercas, por hablar de los más conocidos), pero que sin duda lo es en la literatura y el cine argentinos.
} 
se hizo en Uruguay durante la dictadura de los '70 y le proporciona así a Urbano y al lector los marcos con arreglo a los que representar adecuadamente lo que acaba de saber sobre lo ocurrido en la España de los ' 40 .

Desde Uruguay y sobre todo Argentina hasta España, desde los '70 del Siglo XX hasta el Siglo XXI para entender los ' 40 del XX, el desaparecido ha hecho un largo viaje. Para entenderlo podemos acudir a una hipótesis soft, propia de estudios, los transatlánticos, interesados en objetos que atraviesan el Océano en desplazamientos de ida y vuelta, en movimientos de cruce, disputa y (re)apropiación de direcciones múltiples, tanto en tiempo como en espacio. Como un grupo pop, un icono deportivo chino o unas zapatillas Nike, el desaparecido transatlántico podría ser uno de esos objetos: nacido en América, viaja a Europa, renuncia a su origen y compone una identidad de límites más porosos y contenidos más fluidos. Visto así, del desaparecido, de su concepto quiero decir, no sería relevante saber cómo se produce sino cómo circula; más que el "tiempo histórico", el del origen y la autenticidad, importaría de él "el tiempo trans-histórico", el de las reinterpretaciones, ése en el que se "entrecruza[n] relatos" y las cosas son "una y otra vez actualizad[as]" (Ortega, 2010: 84).

Considerando que mucho más pertinente que atender a la producción de los conceptos que estructuran el campo de los derechos humanos (derecho, refugiado, desaparecido, víctima, reconocimiento, perpetrador, reparación, entre muchos otros), lo es observar los usos locales de esos conceptos univer- sales, trabaja mucha de la investigación antropológica en este terreno. Es el caso de aquellos ejercicios que, para hablar de los desaparecidos en España, estudian cómo se digiere esta figura entre los colectivos que recurren a ella a la hora de definir su posición en el recién estrenado, y aún frágil, campo español de los derechos humanos y de la memoria. ${ }^{5}$ Si la de los estudios transatlánticos era sensible al movimiento de desautentificación, esta segunda hipótesis lo es al de apropiación local de las figuras propias del campo de los derechos humanos, esto es, a esa vernacularización de los derechos ${ }^{6}$ que comporta necesariamente la práctica de los agentes de ese campo en situación.

La primera hipótesis despeja las tentaciones de elaborar para el desaparecido una historia lineal y nos recuerda, de nuevo, el carácter abierto e inestable de todo objeto que circule en el campo social, más aún si concierne a lo que el desaparecido concierne, lo humano mismo. ${ }^{7}$ La segunda nos refresca la memoria a los que a veces olvidamos que los contextos de justificación y uso importan muchas veces más que los de producción, tanto en lo que a los conceptos científicos refiere como en lo que atañe a los propios del vidrioso terreno de los derechos humanos. No obstante, sí aspiramos a entender cómo ha sido que el detenido-desaparecido ha alcanzado el estatuto de figura culmen del derecho internacional en materia de vulneración de los derechos humanos, cómo ha sido que se ha elevado al altar de los conceptos universales, transatlánticos y transhistóricos, cómo ha sido además que todo eso ya está jurídicamente refrendado, creo que es necesario presentar una ter-

\footnotetext{
${ }^{5}$ Francisco Ferrándiz se ha acercado a ese trabajo de descarga de un concepto del derecho internacional en la práctica diaria de las asociaciones pro derechos humanos en 2010. Un esfuerzo similar es el que realiza en este número de Política y Sociedad Alejandro Baer al acercarse a otro proceso equiparable, la importación del referente del Holocausto a la lectura española de la memoria. Aunque los fenómenos son bien distintos, tanto como lo son los soportes sociales, ideológicos y mediáticos que (los) movilizan, lo que ambos describen es en esencia similar: construcción de un paradigma con valor de referente normativo (el detenido-desaparecido del sur de América Latina, la Shoah), internacionalización de la referencia, consumos localmente diferenciados de ese referente normativo "cosmopolita y transnacionalizado".

${ }^{6}$ En expresión de Jane Cowan (2006, "Culture and Rights after Culture and Rights", American Anthropologists, 108, 1: 9-24), que tomo, como muchas de las consideraciones de este párrafo, de Ferrándiz (2010: 162-163).

${ }^{7}$ Una historia que, de hacerse, debería parecerse a una genealogía. No podría ésta parar en los '70 rioplatenses, pues aunque el significante "detenido-desaparecido" nazca allí, hay prácticas represivas anteriores (el Nacht und Nebel nazi, la Argelia francesa, el Vietnam estadounidense, el GULAG ruso...) que permitían imaginar antes de los 70’ algo de ejecución y consecuencias similares. También deberían considerarse en esa genealogía situaciones más prosaicas, o, mejor dicho, igualmente dramáticas aunque no teñidas de la tonalidad de los genocidios, esto es, los "proyecto[s] global[es] en [los] cual[es] el ejercicio del terror y su difusión en el conjunto social es elemento constituyente y fundamental" (Feierstein, 2011). Pienso en el tratamiento (jurídico entre otros) como desaparecidos de marineros o pescadores muertos en el mar, de personas fallecidas en desastres naturales, de caídos en frentes de guerra cuyos cuerpos no son encontrados.
} 
cera hipótesis. La que propongo pasa por situar los dos desplazamientos del detenido-desaparecido - el horizontal entre continentes, el vertical desde la definición "de derecho" a sus usos y apropiaciones por parte de los agentes que trabajan con ella - dentro de un movimiento generalizado en el comienzo del Siglo XXI, el de consagración de los derechos humanos como uno de los discursos dominantes para percibir el mundo y sus variantes.

La consagración de los derechos humanos como guía de lectura del mundo puede analizarse con referencia al largo, al medio y al corto término. En el largo término cabe acudir a la historia, plena de vaivenes, éxitos y fracasos, del humanismo ilustrado, y, dentro de ella, a la elevación al estatuto de evidencia compartida de lo contenido en la Declaración Universal de los Derechos del Hombre. Es lo que, con rigor de historiadora, analiza Lynn Hunt (2009): los derechos humanos son hoy evidencias compartidas, pero ninguno de ellos se entendería sin acudir a la idea griega de persona, o a la romana de ley o de derecho, o a la cristiana de alma (ibidem: 19) o sin considerar que en su horizonte está la eminentemente moderna de individuo soberano y autónomo. La historia de los derechos humanos es, pues, la de la civilización occidental, aunque se haya convertido hoy en vara de medida para toda subjetividad.

En el medio plazo, esto es, en el tiempo que arranca en la posguerra de la Segunda Guerra Mundial, es ineludible la referencia a ACNUR y 1951, pistoletazo de salida para uno de los dos bastiones ejecutivos de los Derechos Humanos hoy, la ayuda humanitaria internacional (Agier, 2008), y a los juicios de Nuremberg y 1945-1946, acto fundacional del otro bastión, la justicia transicional y el derecho humanitario internacional (Teitel, 2003). ${ }^{8}$ En relación a la primera, Didier Fassin y Michel Agier han aplicado, con armas distintas, críticas de enorme voltaje a la cultura y el mundo humanitarios. Sin dudar de la bondad de sus propósitos ni de la necesidad de su trabajo, Michel Agier ha afirmado de ellos que son "la mano izquierda del imperio" (2008: 296) y, lo que me interesa más, que contribuyen a establecer un régimen de pensamiento sostenido por "una ficción totalitaria" (ibidem: 291) o, cabría mejor decir, totalizante: la de la existencia de una humanidad con identidad compartida y universal. Didier Fassin, por su parte, entiende que la intervención humanitaria es una "política de vida" que administra la existencia en situaciones de "adversidad global" (2007: 508). Es capaz de distinguir entre vidas que deben ser salvadas y vidas que se ponen en riesgo, segrega, unifica, recorta, divide. Así es, el humanitarismo se ha establecido como uno de los marcos de referencia normativo, moral y jurídico propios del mundo globalizado; es la punta de la lanza, dicen Fassin y Rechtman, de una "enorme innovación social", a partir de la que se han consolidado sustantivas mutaciones en "la economía moral contemporánea" (2007: 19), aquellas que han instituido como sin quererlo a la humanidad como un referente moral globalmente compartido.

En cuanto a la justicia transicional y al derecho humanitario internacional, Ruti G. Teitel (2003) propone acercarse a ambos considerándolos como esfuerzos normativos que tienen efectos concretos, entre otros, el de reconstruir la historia filtrándola por el cedazo de los derechos humanos, una perforadora necesaria para la construcción de un consenso global sobre lo humano, sobre su vulneración y sobre cómo reaccionar. Aquí, siempre, el derecho violenta, en el sentido que conmueve y modifica, la realidad sobre la que se aplica (cf. García Blanco, 2011 y Rodríguez Maeso, 2011, en este número de Política y Sociedad), y lo hace con la legitimidad, de difícil cuestionamiento, de quien aspira a universalizar el esquema básico de los derechos universales, justo aunque etnocéntrico, universal en su pretensión aunque local en su fundación. ${ }^{9}$ Bajo el paraguas universalizador de "justicia transicional", la ingente batería de leyes que dotan de armazón al derecho humanitario internacional - leyes de víctimas, leyes de memoria, leyes de reconciliación, leyes de reparación, leyes de reconocimiento, leyes de acceso a la información, leyes de perdón y olvido...- opera por doquier de un modo altamente performativo: crea verdad, consenso, secuencias legitimadas de memoria, y al tiempo, contribuye a la creación de

\footnotetext{
${ }^{8}$ Tengo que agradecer en este punto los comentarios, prudentes y agudos, de Ramón Sáez a esta parte mi argumento.

${ }^{9}$ Una revisión histórica sorprendentemente etnocéntrica puede encontrarse en Jon Elster, 2006. Un trabajo comparativo muy bien sostenido puede leerse en Mihaela Mahi, 2010.
} 
nuevos sujetos colectivos, de nuevo las víctimas, los sujetos asistidos por esa batería legislativa.

En cuanto al corto plazo, el contexto de la "guerra global contra el terrorismo" ha supuesto una verdadera ruptura en la historia de los derechos humanos, tanto en su conculcación - pues las situaciones que los exceptúan se han vuelto norma (Agamben, 1998) - como en su defensa — pues se multiplican también las situaciones en las que la práctica humanitaria puede llevarse a efecto, que son precisamente, aquellas que exceptúan la aplicación de la norma universal sobre derechos humanos (Fassin, Vasquez, 2005) - Como ha observado Rosa Linda Fregoso (2006), de igual modo que en el contexto de los últimos años se han dado las condiciones para una proliferación insólita de espacios de exclusión para la aplicación de los derechos humanos (la red planetaria de centros clandestinos de detención; la de "zonas de tránsito", "centros de acogida", "campos de desplazamiento"... para refugiados en África y América; la de "centros de detención indefinida" como Guantánamo; la de "campos de retención" de emigrantes en Europa; la ley de nombre "Tratamiento de algunos no-ciudadanos en la guerra contra el terrorismo", de diciembre de $2001 \ldots$ ), ese mismo contexto ha operado también como condición de posibilidad para un auge insospechado de lo humanitario. Puede argumentarse entonces que en el contexto de la guerra global contra el terrorismo se ha activado un doble movimiento: de un lado, el que conduce al incremento de las excepciones a la ley; de otro, el que lleva al desarrollo de un sensorio irritable frente a las situaciones de vulnerabilidad extrema que esas excepciones desencadenan. Todas estas situaciones se enlazan en una suerte de campo de lo vulnerable que ha encontrado su lingua franca en el lenguaje de los derechos humanos.

Es en ese contexto, el del auge de la moral humanitaria y de la generalización de sus artefactos, que una figura vieja cobra brío y se eleva a la cúspide de los tipos subjetivos que organizan la identidad social en el mundo contemporáneo, la de la víctima. En efecto, más allá de que obviamente el significante preceda, y por mucho, a la era de lo humanitario, muchos son (Mate, 2008; Wieviorka, 2003) los que han propuesto que el de víctima es un tipo subjetivo de nacimiento reciente. Queriendo trazar su genealogía, Michel Agier ha observado que la edificación de una cultura humanitaria de dimensiones planetarias pasa necesariamente por la construcción de un doble correlato: en primer lugar, entre humanidad y ayuda humanitaria ("ficción - dice Agier - de equivalencia entre un régimen de pensamiento universal (la humanidad (...)) y un dispositivo mundializado [la red de ayuda humanitaria]" (2006: 4)); en segundo lugar, entre humanidad y víctima. Si el primero es de fácil visualización — "nada de lo humano es ajeno a la cultura humanitaria", podría ser el lema-, el segundo correlato es de construcción más compleja: no se trata de decir que esa humanidad de identidad una sea toda ella de víctimas (por mucho que sea cierto que la experiencia traumática se haya convertido en un lugar de paso necesario para pensar hoy la experiencia individual o colectiva (Fassin y Rechtman, 2007: 39))—. El lugar de la víctima es más funcional que sustantivo: víctima es un lugar necesario para definir la humanidad, un tipo subjetivo que señala el borde último, la frontera, de lo humano y por mediación del que la humanidad se define. Es, podría decirse así, lo humano en déficit, casi el contrasujeto del viejo sujeto humanista e ilustrado. La víctima, humano en (el) extremo, hace posible lo humano mismo.

Construido de ese modo, víctima es entonces un referente en el que encaja fácilmente el detenidodesaparecido, pues esta figura posee, en efecto, las credenciales adecuadas para tomar buenas posiciones en la contemporánea "jerarquía de la desdicha" (Agier, 2008: 81): figura extrema en el escalafón de lo humano vulnerado, en la que se ponen en juego dos de los pilares de la lectura moderna occidental del sentido, la identidad individual y el proceso civilizatorio; en la que se quebrantan derechos en los que intervienen bienes leídos, también en el occidente moderno, como esenciales e inalienables (vida-muerte, nombre-cuerpo, memoria-historia, comunidad-identidad colectiva...)... Una víctima total.

A mi juicio, es con arreglo a todo ello que puede entenderse el éxito de la construcción de una definición internacionalmente consensuada del desaparecido transnacional, un sujeto extremadamente vulnerable, la víctima total, el límite mismo de lo humano, un doliente universal... 
3. EL DESAPARECIDO MODÉLICO. LAS ESTRUCTURAS DE SENTIDO QUE LA DESAPARICIÓN FORZADA DE PERSONAS MOVILIZA (Y DESPEDAZA)

...y sin embargo, local en su origen. Así es, si el éxito de este desaparecido del derecho y la práctica humanitarias es global, la figura, en origen, tiene una explicación de coordenadas muy locales. Argumentaré esto en dos pasos: primero atendiendo a cómo se representa y vive y qué comporta la figura del desaparecido construida en el contexto local que produjo la definición del detenido-desaparecido modélico, esa que luego ha devenido global, el argentino; luego, en el siguiente epígrafe, observando, muy brevemente, cuáles son los elementos centrales de la definición jurídica que construyen instancias internacionales como la Convención Interamericana sobre Desaparición Forzada de Personas o las Naciones Unidas. A la reducción de complejidad, notable, que caracteriza el paso de lo primero a lo segundo, acompaña un incremento, también notable, en la eficacia (política, jurídica).

El desaparecido modélico, ése en el que la definición más asentada de la desaparición forzada se inspira, es el que surge de la Argentina de la dictadura militar de los años 1976-1983 y en alguna medida de las de Uruguay, Chile y parcialmente Brasil de la misma década. Lo que sigue resume lo que, en esencia, estructura a este desaparecido modélico. Lo expondré a través de la sucesión de diez proposiciones ordenadas en dos bloques: primero daré cuenta de la desaparición en sus causas (el aspecto etic de la desaparición forzada de personas: las raíces sociohistóricas de la maquinaria de desaparecer personas y cuerpos; la lógica que guía la aplicación de ese dispositivo de deglución de personas y cuerpos); luego explicaré la desaparición en sus efectos (su aspecto emic: las consecuencias que deja la maquinaria desaparecedora sobre aquellos que sobreviven a su acción y sobre el espacio social donde se ejecuta). Lo que sigue es breve $-\mathrm{y}$ asume por eso los riesgos de lo sintético- y tiene forma de decálogo - y asume por eso los riesgos de lo normativo-; no obstante, sus diez proposiciones se basan en un trabajo de campo largo y sistemático. ${ }^{10}$

\subsection{La desaparición forzada de personas en sus causas}

\section{Primera proposición: la desaparición forza- da deriva del mismo proceso histórico que constituyó (I) la civilización}

La desaparición forzada de personas pone en juego tres elementos, que son, por lo demás, los que soportan parte importante del sentido de la acción y la identidad modernos: la civilización, el Estadonación, el individuo-ciudadano.

En cuanto a la civilización hablo de un proceso de largo aliento, en el que se combinan las economías subjetivas (Elias, 1988) con las que tienen que ver con los procesos que transcurren en dimensiones macrosociales, más visibles. Sobresalen en ello tres grandes vías civilizatorias: (1) la que conduce a la formación de una población (Foucault, 1990) (es decir, de un territorio para la acción de gobierno compuesto por individuos-ciudadanos unidos en conjuntos con forma de Estado-nación); (2) la que lleva a la formación de la sociedad a golpe de letra e idea (Rama, 1988), esto es, desde la ejecución del sueño del jardinero (Bauman, 1997), el del orden y progreso, el de concierto y la educación, el de la utopía y la libertad, el de la civilización contra la barbarie; (3) la que termina por rellenar ese mundo hecho a golpe de cincel moderno con individuos civilizados (Elias, 1988).

\footnotetext{
${ }^{10}$ Que, por si se desea, en Gatti, 2008 se encuentra desarrollado con bastante más pausa. Aquel texto deriva de un largo trabajo de campo que se realizó entre 2005 y 2008 entre Buenos Aires y Montevideo y que fue financiado por los programas de movilidad de la Universidad del País Vasco y del Gobierno Vasco. Se aplicó un abanico de técnicas de investigación cualitativa, desde las propias de una investigación participante - muy marcada en este caso por la asunción de que el investigador forma parte de la acción que se observa, que uno es "finit[o] y suci[o] y no limpi[o] y trascendente" (Haraway, 2004: 55), en este caso la suciedad objetivante que viene de mi doble condición de sociólogo y familiar de desaparecidos-, hasta entrevistas en profundidad y grupos de discusión.
} 
Segunda proposición: la desaparición forzada deriva del mismo proceso histórico que constituyó (II) al Estado-nación

Esa sociedad ideal, letrada, plena de ciudadanos que integran una población homogénea de cara al exterior e internamente heterogénea, se parece a un Estado-nación y está poblada de un sujeto con forma de individuo-ciudadano. El primero es el modelo de la vida colectiva moderna y es también su resultado, al punto que ha devenido nuestro productor de solidez (Lewkowicz et al., 2003: 171). Constituye, sí, "nuestra canción", la melodía que nos atrapa, la única manera que tenemos de ver y vivir la vida social. No hablo sólo de una referencia empírica, que sí, ni de una realidad administrativa, que también. Hablo de nuestra "pan-institución donadora de sentido", del "principio general de consistencia" de nuestra subjetividad (ibidem: 31 y 65), de aquello que para nosotros, modernos, supone, no es poco, nuestra geometría básica (Moya, 1984). Hablo del Estado-nación como de aquello que ordena y coloniza nuestra subjetividad.

\section{Tercera proposición: la desaparición forzada deriva del mismo proceso histórico que cons- tituyó (III) al individuo-ciudadano}

Si el Estado, en su dinámica higienizadora y racionalizante (véanse proposiciones cuarta y quinta) fue el agente activo de la desaparición forzada de personas, su agente pasivo fue el individuo-ciudadano. No es éste cualquier persona; es el ciudadano moderno, un sujeto racional e ilustrado, aseado (o sucio por elección). Es un sujeto que tiene historia, la misma que los derechos humanos por cierto, la misma también que el mecanismo que lo devasta. Pero sin embargo, del mismo modo que a los derechos humanos, al individuo-ciudadano hoy se le piensa como una entidad ahistórica o incluso como un universal sociológico. No lo es; al contrario, es algo de invención reciente: "En la praxis social de la antigüedad clásica la identidad grupal del ser humano particular, su identidad como nosotros, vosotros y ellos, todavía desempeñaba, comparada con la identidad como yo, un papel demasiado importante para que pudiera surgir la necesidad de un término universal que representara al ser humano particular como a una criatura casi desprovista de un grupo social" (Elias, 1990: 182).

\section{Cuarta proposición: la desaparición forzada de personas no es barbarie, sino modernidad exacerbada}

La desaparición forzada no es barbarie, sino modernidad en estado paroxístico, parte del sueño de una sociedad vista como "un objeto a administrar, como una colección de distintos problemas a resolver, como una naturaleza que hay que 'controlar', 'dominar', 'mejorar' o 'remodelar', como legítimo objeto de la 'ingeniería social' y, en general, como un jardín que hay que diseñar y conservar a la fuerza en la forma en que fue diseñado" (Bauman, 1997: 23). Aunque es tentador recurrir al argumento de que las dictaduras, la tortura o, en una escala de brutalidad superior, la de la desaparición forzada, contravienen una suerte de regla de progreso de los procesos civilizatorios, quizás sea más ajustada a lo que ocurrió la hipótesis que sostiene que a lo que asistimos es a la exacerbación de la racionalidad.

\section{Quinta proposición: la desaparición forzada de personas es un dispositivo de racionaliza- ción del mundo}

Si un dispositivo es un medio de racionalización del mundo que construye aquello sobre lo que se aplica, la desaparición forzada de personas indudablemente lo es: es una técnica que hace lo que dice, un mundo menos lleno de molestias. Así es, ingiere cuerpos enteros, los deglute y expulsa restos, suciedades, a saber: cuerpos sin nombre, identidades sin cuerpo. Un antropólogo forense integrado en el EAAF (Equipo Argentino de Antropología Forense) lo explica con frío rigor científico: "El terrorismo de estado disoció y retaceó: [hizo] que una identidad y un cuerpo se separasen [Rompió] la relación básica que todos tenemos entre nuestra identidad y nuestro cuerpo". Otro de ellos lo completa con enunciados de textura y temperatura similar: "El fenómeno de la desaparición asemeja a un sistema de ingreso y egreso" (Fonderbrider, 1997). 


\section{Sexta proposición: la desaparición forzada de personas es un dispositivo que se desplie- ga en el territorio de la identidad}

La imagen establecida acerca de lo que significa, en el Occidente moderno, tener identidad requiere de aquella entidad para la que se supone esa virtud que esté sujeta a tres unidades indisolubles: (1) la unión de un nombre y un cuerpo - con forma de individuo - que (2) engarza en una historia colectiva - con forma de novela familiar - que le permite imaginar el suyo como un tiempo con duración y que, por último, (3) ancla en el presente en una comunidad firme, estable, duradera - que tiene, entre nosotros, forma de Estado-nación-. Si cumple con eso, esa entidad podrá decirse poseedora de un Nombre propio; propietaria de una Historia singular; dueña de un Territorio diferenciado. Tendrá, pues, identidad (Gatti, 2007).

Lo que la desaparición forzada de personas desbarata es esa arquitectura de la identidad. Despedaza primero la que se lee como unidad ontológica del ser humano, la que reúne un cuerpo y sólo uno con un nombre y sólo uno: el cuerpo - que no se encuentra- se separa del nombre - que flota eternamente sin soporte físico-. Despedaza luego la unión de ese nombre y ese cuerpo asociados a la continuidad de la novela familiar —el individuo se separa de su historia: queda encerrado en el eterno presente del desaparecido; a sus progenitores se les "amput[a] el acceso al estatuto de ancestro" (Héritier, citada en Imaz, 2008); a sus sucesores, los "hijos de", se les propone el tiempo desarticulado de la orfandad (Gatti, 2010a) - . La maquinaria despedaza por último la relación de ese individuo a la comunidad sancionada por el Estado, esto es, lo expulsa del pacto de ciudadanía.

\subsection{La desaparición forzada de personas en sus efectos}

\section{Séptima proposición: la desaparición for- zada es imaginada como un desajuste sin arreglo}

Y a partir de ahí, el desastre, el desnorte, la pérdida de referencias. Así es, una vez instalada entre los afectados la convicción de que lo que pasó no fue normal, que era algo raro, se hace difícil agarrarlo con los armazones que sujetan normalmente la subjetividad. Por eso, los sujetos concernidos, hijos, esposos, madres, hijas, parejas, compañeras, padres, dicen tras el tsunami cosas como éstas, que hablan bien claro del desconcierto que padecen: ${ }^{11}$

"El desaparecido no deja rastros, crea un vacío"

"[Con ellos] la ausencia se convierte en presencia"

"Es un cuerpo sin identidad y una identidad sin cuerpo"

"Un desaparecido ni está vivo ni está muerto, es un desaparecido"

"Antes había personas que morían. Y ahora hay desaparecidos, una no persona, algo que no se sabe si existe"

"La desaparición es un atentado a la lógica. Provoca un sentido de absurdo"

"No existen, es una entelequia, no tienen entidad"

"Al no estar el cuerpo es imposible hacer el duelo. Nos queda la incógnita de ese cuerpo que nos niegan. Sin él, no podemos elaborar la muerte y darle la sepultura que se merece. Es el ser y no ser. La angustia se transforma en letanía. Las preguntas no cierran y la tragedia tampoco cierra. Una se interroga permanentemente. Nuestros hijos no están muertos. Están desaparecidos"

Lo normal se truncó: se rompieron las genealogías; quebró la posibilidad de las cosas dadas por

\footnotetext{
${ }^{11}$ Todas estas frases están extraídas del trabajo de campo ya referido. Cf. Gatti, 2008.
} 
supuestas. Se resquebrajan los materiales gracias a los que representamos, ordenamos y administramos el mundo, los usos y costumbres heredados o inventados, las rutinas, en fin, con las que colmamos el tiempo de sentido. A partir de la desaparición forzada, todo eso se imposibilita, incluida la administración convencional de la muerte: aquí no hay cuerpos, ni restos, ni tumbas. "En los procesos 'normales' de muerte - explica Ludmila da Silva Catela - donde existe un cuerpo para dar sepultura, el cementerio es la frontera que separa el mundo de los vivos del mundo de los "muertos" (2001: 114). Pero aquí no hay cuerpos. Ni restos. Ni tumbas ¿En qué lugares plantar la muerte? ¿Cómo hacer duelo sin la materialidad del cuerpo presente?

\section{Octava proposición: la desaparición forzada es devastadora porque compone paradojas irresolubles}

En su desarrollo, el dispositivo desaparecedor operó de manera que la rutina civilizatoria - la que crea, entre otras cosas, individuos-ciudadanos - se aplicó a lo más acabado de la civilización —entre otras cosas, a individuos-ciudadanos-. Esa es la "paradoja del detenido-desaparecido" (Gatti, 2010b) y se enuncia así:

1. la desaparición forzada es parte de las herramientas de construcción y gestión de la población propias del orden civilizatorio/moderno;

2. la desaparición forzada se aplica a los productos más acabados del orden civilizatorio/ moderno.

La desaparición forzada de personas actúa entonces como una máquina civilizatoria invertida: crea una figura que, más que bárbara, es des-civilizatoria, el propio desaparecido, una enorme novedad histórica. Así es, en los 70' se puso en marcha un proceso enormemente novedoso: las entidades objeto de desaparición forzada, esto es, objeto de fuerza civilizatoria, fueron los productos más refinados del resultado del ejercicio del propio trabajo civilizatorio, los individuos con carta plena de ciudadanía, aseados, racionales e ilustrados. Los frutos perfectos de la modernidad son los que fueron despedazados por la maquinaria que los gestó.

\section{Novena proposición: la desaparición forzada es una catástrofe}

La desaparición forzada de personas es una catástrofe, esto es: un desarreglo permanente de los aparatos de construcción social de sentido y subjetividad.

Existen hechos asociados establemente a sentidos y también hechos disociados totalmente del sentido. Esta disociación puede producirse de manera puntual o de manera duradera. En este último caso tenemos problemas para representar y vivir las situaciones marcadas por esa disociación; si además esa disociación se estabiliza, tenemos una catástrofe. Sea una serie, la que empieza en lo socialmente imaginado como normal y termina en su contrario: el grado cero es la normalidad (hechos hermanados a sentidos); a él le siguen tres grados de disociación entre hechos y sentidos, el trauma, el acontecimiento y, en el límite de lo pensable, la catástrofe:

1. En el trauma la desestabilización es profunda pero provisional pues hay instituciones con capacidad de regular los desajustes, competentes para que a la desestabilización siga la institucionalización de un nuevo equilibrio. Pasado el tiempo, todo regresa a su lugar; se normaliza. La muerte de un cercano es un trauma; el duelo, cuando se cierra y se resuelve, es una institución para gestionarlo.

2. En el acontecimiento la desestabilización es profunda e intensa. Tanto que mientras sucede el desencaje es absoluto, pero dura poco. De tan intenso, no hay categoría para comprenderlo, atraparlo, decirlo. Así, el acontecimiento se afirma como lo único y sin nombre, pero se desvanece rápido; tanto que deja pocos ejemplos: irrupciones de dolor; revueltas poderosas; placeres inmensos. No dejan huella.

3. La catástrofe es la inestabilidad estable: el desajuste permanente entre palabras y cosas convertido en estructura en tanto tal desajuste. "La catástrofe es una dinámica que produce desmantelamiento sin armar otra lógica equivalente en su función articuladora" (Lewkowicz, 2002: 154). La causa de la catástrofe no se retira: el desastre es permanente, la anormalidad deviene 
norma, el duelo es perpetuo... "Esta vez la inundación llega para quedarse" (ibidem).

Cuando una catástrofe ocupa la vida social, se construye en torno suyo un espacio muy problemático, difícil de vivir y de pensar, un espacio que se define por la quiebra de las relaciones convencionales entre la realidad social y el lenguaje, donde esta quiebra se consolida y las dificultades para representar lo que ocurre en los territorios que la quiebra dibuja son permanentes. Tras el tsunami se vive, pero cuesta.

\section{Décima proposición: alrededor de la catás- trofe de la desaparición forzada de personas se construye un campo social (el "campo del detenido-desaparecido")}

La desaparición forzada va, en el tiempo, mucho más allá del "desastre fundacional", no solo porque las heridas nunca cierran, no solo porque el muerto nunca muere ni porque el delito sea permanente, sino también porque alrededor suyo nace primero y cristaliza después un universo social, el universo de la catástrofe, en el que son muchos los agentes instalados. Ese universo se estructura en forma de campo social y como todo campo, de éste se puede trazar una genealogía. Para el caso argentino, la de su campo del detenido-desaparecido se mueve en paralelo a la de la aparición misma del concepto: que primero no existía —en los primeros ' 70 ni siquiera los familiares de los que luego serían llamados así usaban el término, al que solo se empezó a acudir cuando algunos datos daban a entender que esto que les estaba pasando no era "lo mismo de siempre"-, ${ }^{12}$ que más adelante se administró en el terreno de campos de creación reciente pero previamente institucionalizados, los de las luchas por los derechos humanos (Jelin, 2003), y que sólo con el tiempo se consolidó tanto que habilitó a la construcción de un universo en torno a él. Hoy ese campo existe ya como singularidad naturalizada: tiene su centro en una figura extraña - el desaparecido no cabe en ninguna taxon conocida: ni vivo ni muerto, ni presente ni ausente-; tiene también retóricas consensuadas en torno a esa figura (la de la memoria, la de la ausencia, la del silencio, la del vacío...); invita al desarrollo alrededor suyo de distintas experticias (archiveros, psicólogos, historiadores, antropólogos forenses...); tiene lenguajes propios (como las peculiares categorías para nombrar a los familiares de detenidosdesaparecidos), producciones artísticas y culturales singulares y articula un poderoso conjunto, profundamente familista (Gatti, 2010a; Jelin, 2011) de agentes, instituciones y movimientos sociales (Madres, Abuelas, Hijos, Hermanos... de desaparecidos, asociaciones de ex desaparecidos, organismos públicos, centros de investigación...) que giran en torno a una figura, la del detenido-desaparecido, que se ha consolidado siendo imaginado como un fenómeno que afecta e imposibilita que la identidad se represente y viva como se vive y representa normalmente en Occidente.

\section{EL DESAPARECIDO INMUTABLE. CABALGANDO POR EL MUNDO A LOMOS DEL DERECHO HUMANITARIO}

"Donde existe la misma razón debe existir la
misma disposición". Aforismo jurídico

Fue, por sus efectos, una verdadera catástrofe: "Unos bestias pintaron La Gioconda y en realidad estaban tratando de matar una mosca con un pincel (...). Hicieron cosas increíbles, separaron una identidad de un cuerpo, eso es lo que hicieron". Dieron forma a un estado inédito para el que no existía nombre, a "un abismo nuevo", a algo que va más allá de cualquier cosa conocida, el propio detenido-desaparecido.

De ese modo resumen dos de mis entrevistados lo que entienden por desaparición forzada de perso-

\footnotetext{
${ }^{12}$ Sobre el nacimiento de esta entidad y sobre cómo los familiares fueron digiriéndola, $c f$. para el caso argentino el libro de Ludmila da Silva Catela (2001), que recoge el resultado de sus investigaciones acerca de cómo la novedad de la figura comportó la necesidad de inventar lenguajes nuevos para decirla y pensarla, pues, explica, "las categorías conocidas y usadas para indicar a las personas ligadas a un muerto no eran simbólicamente eficaces" (2001: 116). En efecto: el lenguaje del parentesco existente no servía, pues ni sus hijos eran huérfanos (un hijo de un no-muerto-no-vivo ¿qué es?), ni sus parejas eran viudos (un deudo de un no-muertono-vivo ¿qué es?).
} 
nas: ${ }^{13}$ algo más allá del límite, un nuevo estado del ser que nace de la acción del Estado, acción que retira a un ciudadano sus credenciales, que cercena las bases de su identidad y que, literalmente, lo absorbe, sumergiéndolo en un espacio de excepción, fuera del alcance de la ley e incluso del concepto mismo de ley. No es una mala síntesis de la desaparición forzada de personas en su "acepción argentina", la originaria.

Es una acepción fuerte, cargada. Es además la que servido de vara de medir de todo otro resultado de prácticas de desaparición forzada de personas. Así es, sea o no el Estado el ejecutor, haya o no haya habido paradero desconocido del sujeto desaparecido, haya sido o no selectivo y sistemático el proceso de elección de víctimas el dispositivo desaparecedor, sea un individuo, un grupo étnico, una comunidad rural o una de creyentes el destinatario, la acepción argentina ha tenido éxito, enorme. Hoy, el concepto de desaparecido que inventa la que la literatura de ciencias sociales argentina llama, ignoro si con ironía o por mero convencionalismo, "la última dictadura", es ya refrendado por el derecho humanitario internacional.

Lo fue primero por parte de la Convención Interamericana sobre Desaparición Forzada de Personas, adoptada en junio de 1994, que ayudó a entrever cuál es el sujeto paciente de esta práctica represiva: "La desaparición forzada de personas viola múltiples derechos esenciales de la persona humana de carácter inderogable (...): el derecho a la libertad y la seguridad de la persona, el derecho a ser reconocida en todas partes como una persona ante la ley, el derecho a la defensa, el derecho a no ser sometido a la tortura, y constituye una grave amenaza al dere- cho a la vida". Lo fue finalmente por la Convención Internacional para la Protección de todas las Personas contra las Desapariciones Forzadas, adoptada el 20 de diciembre de 2006 por la Asamblea General de las Naciones Unidas y ratificada en febrero de 2007, que en su segundo artículo describe de este modo la desaparición forzada: "El arresto, la detención, el secuestro o cualquier otra forma de privación de libertad que sean obra de agentes del Estado o por personas o grupos de personas que actúan con la autorización, el apoyo o la aquiescencia del Estado, seguida de la negativa a reconocer dicha privación de libertad o del ocultamiento de la suerte o el paradero de la persona desaparecida, sustrayéndola a la protección de la ley" (Las cursivas son mías).

Así pues, un sujeto activo, el Estado, que sustrae a un sujeto del imperio de la ley y lo sumerge en un espacio que la exceptúa, y un sujeto pasivo, que no es cualquiera: es un individuo, un ciudadano, un sujeto moderno, que tras la desaparición deviene un paria, un desolado, un "expulsado de lo humano": ${ }^{14} \sin$ nombre, sin cuerpo, sin historia. Ya no es un ciudadano, ya no es reconocible como un individuo de los de nombre y apellido; pasa a ser nombrado a través de un término, desaparecido, que no se conjuga como un participio -está desaparecido - sino que se enuncia como un sustantivo - es un desaparecido-.

Hoy, a lomos de la definición que de él aporta el derecho humanitario internacional, el detenidodesaparecido viaja de un continente a otro, de época en época, sin sufrir demasiado los desajustes que tan largos desplazamientos deberían depararle. Endurecido, el desaparecido se ha convertido en un verdadero móvil inmutable: $:^{15}$ nació, y nació complejo,

\footnotetext{
${ }^{13}$ El primer fragmento corresponde a la entrevista realizada a un miembro del Equipo Argentino de Antropología Forense; el segundo a la que mantuve con un ex detenido-desaparecido.

${ }^{14}$ Desde el psicoanálisis Edmundo Gómez Mango, apoyándose en Hanna Arendt, propone incluir al detenido-desaparecido en la nómina de los desolados — precarios, clandestinos, sin papeles, refugiados...-, parias marcados por la pérdida y la ausencia, sujetos de duelos no resueltos: "La noción de desolación concebida por Hanna Arendt me parece la que mejor se presta para describir y comprender el sufrimiento psíquico de estos parias de la modernidad (...), 'una situación en la que, en tanto que persona, me siento apartada de toda compañía humana" (2006: 101), una señal de la "experiencia íntima de sentirse radicalmente expulsado de lo humano" (ibidem: 8).

${ }^{15}$ Un móvil inmutable es un objeto que se desplaza enormes distancias (físicas o imaginarias) y que sigue siendo lo mismo a la salida que a la llegada: una botella de Coca Cola leída tal aquí y en USA, una pelota de fútbol sabida "pelota de fútbol" en Nairobi y en Guayaquil, una persona pensada como individuo en Toronto y en Montevideo, un detenido-desaparecido en Argentina, Guatemala o España... Para construirlo, explica Bruno Latour, es preciso un persistente trabajo de endurecimiento de los hechos (1985: 10): convertir realidades blandas, difusas, de límites indefinidos, a veces incluso de límites indefinibles, en ocasiones incluso irrepresentables... en objetos duros, en materia transportable y comparable, en objetos singulares y móviles en tiempo y espacio. La construcción
} 
en los chupaderos ${ }^{16}$ argentinos, que parieron al desaparecido originario. Sufrió luego dos transformaciones: en un primer movimiento, sin perder complejidad, pero sí matices, el desaparecido originario devino, a través de un intenso trabajo de traducción jurídica, desaparecido transnacional; luego, en un segundo movimiento, éste se convirtió en la matriz de referencia con la que se piensan, se miden (y casi nunca se juzgan) los múltiples casos de desaparecidos locales ya integrados en el tipo transnacional.

Desaparecido transnacional (construcción de la figura jurídica)

Paso 1: Desde "la realidad" al texto jurídico (construcción de la figura del desaparecido transnacional)

\section{Desaparecido originario}

(la referencia argentina)

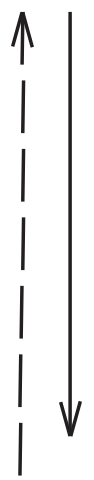

Paso 2: Desde la definición jurídica a "la realidad" (la diversidad filtrada por las inscripciones que la representan)

Desaparecidos locales integrados en el tipo transnacional (diversidad de casos equiparados a la referencia originaria a través del filtro del modelo del desaparecido transnacional: Ingusetia, España, Argelia, Nepal, Guantánamo...)

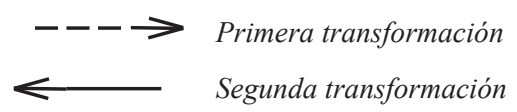

Fig. 1: Desaparecido originario è desaparecido transnacional è desaparecido local transnacional ${ }^{17}$.

\footnotetext{
de un móvil inmutable se opera en cinco pasos sucesivos: movilizar o definir (reducir la realidad a pocos elementos, construir una definición); fijar las formas (sacar al objeto definido en el filtro de su contexto, aislarlo como forma independiente); aplanar (reducir las variedades del objeto a pocos rasgos, a los que quepan en una hoja de papel); recombinar (poder comparar el objeto definido, fijado y aplanado con otros objetos parecidos ya definido, fijados y aplanados); e inscribir (traducir esa entidad definida, fijada, aplanada y recombinada a signos, archivos, documentos, trozos de papel, huellas... (Latour, 2001: 365). Después de esos cinco pasos, el objeto ingresa en el espacio, homogéneo y ordenado, de la geometría (Latour, 1985: 22). Si se aplica a nuestro caso, tras esos cinco pasos es que podemos definitivamente decir lo que el detenido-desaparecido es y distinguirlo de lo que no es; ya podemos moverlo y compararlo sin miedo a que se altere. Queda para otra ocasión la posibilidad de pensar que el detenido-desaparecido pueda ser no un móvil inmutable si no un significante vacio. Eso es lo que me sugirió Daniel Muriel cuando discutimos este trabajo en el contexto de Los tesináculos, a cuyos integrantes (Daniel Muriel, David Gómez, César Oré, Mikel García e Iñaki Robles) agradezco el esfuerzo de digerir una de las primeras versiones de este texto.

${ }^{16}$ Chupadero es el descriptivo término con que los perpetradores y con el tiempo las víctimas de la desaparición forzada de personas nombraban los centros de detención donde eran llevados, sustraídos y absorbidos de la realidad los que luego devendrían detenidos-desaparecidos.

${ }^{17}$ La figura se construye combinando varias de las muchas con las que trabajan Latour y Hermant (1999).
} 


\section{A MODO DE CIERRE: ALGUNAS CONSECUENCIAS (NO INTENCIONADAS) DE LA TRANSNACIONALIZACION DEL DETENIDO-DESAPARECIDO}

Partiendo en los '70 del Cono Sur latinoamericano, el detenido-desaparecido ha llegado lejos, incluso a la España de la Guerra Civil y el franquismo. Largo viaje, en tiempo y en espacio, viaje, por lo demás, ya culminado. Aunque las rígidas exigencias del rigor conceptual me hacen pensar, como a muchos otros, que ni cabe hacer de los ahora llamados desaparecidos de la Guerra Civil figuras equivalentes a los desaparecidos del Cono Sur latinoamericano, ni cabe tampoco entender que sean similares las formas de represión de un lado y otro del Atlántico, aunque entiendo también que han de ponerse límites a los afanes propios de la sociología comparada, pues pueden hacernos olvidar las singularidades históricas y sociológicas de las formas de represión y de producción de terror locales, aunque piense además que subsumir lo ocurrido entonces dentro de tipos penales internacionales creados ahora acarrea el riesgo de perder matices, de perder rigor, creo también que la demanda de matiz y de rigor conceptual no tiene demasiado sentido en un campo como el de los derechos humanos, donde conceptos, ideas y movilizaciones circulan con gran dinamismo. En ese campo, probablemente en todos, es necesario diferenciar entre contextos de producción y contextos de uso de los conceptos, razón por la puede concluirse que, signifique lo que signifique en origen la figura del detenido-desaparecido, los movimientos pro-derechos humanos, la opinión pública y en menor medida los agentes que participan en los debates legislativos y en los pasillos de las sedes del poder judicial se han apropiado ya de ella tiene desde hace un buen rato vida social propia.

Por si no se entendió, en ningún caso pretendo afirmar que haya habido una exportación fraudulenta de ese producto argentino. Ahora bien, sí digo que se ha dado un trabajo de endurecimiento y de estilización del desaparecido originario, que bajo la forma de desaparecido transnacional se ha desplazado, muy simplificado, por doquier, atravesando el mundo gracias a las autopistas de la moral humanitaria, de las ideas de justicia transicional, del derecho uni- versal humanitario, de la vigorosa subjetividad de la víctima. Y que ya está aquí.

Bienvenido sea, pues, el detenido-desaparecido a España. Como muchos otros emigrantes, vino para quedarse, y como pasa con todo emigrante, una vez aquí, ya no es igual a como era cuando salió de sus pagos de origen. Lo que sí es cierto es que la cuestión está lejos de no tener consecuencias:

1. La primera consecuencia es que ahora existen desaparecidos españoles. Pues en efecto, sujetos antaño sin nombrar o nombrados de otra manera son ahora, y cada vez más, llamados desaparecidos, ingresando entonces al poderoso marco de reconocimiento que hoy ofrece el derecho humanitario internacional, un rasero normativo que multiplica exponencialmente la posibilidad de que interesen los sujetos que son objeto de su atención.

2. La segunda consecuencia es que esta figura está operando como uno de los catalizadores más relevantes de un movimiento por la memoria hasta ahora inexistente en España, un movimiento que además canaliza la expansión de los derechos humanos y que, éste si, adopta formas eminentemente locales, como, por ejemplo, la particular gestión de las exhumaciones y de la "socialidad de las fosas" (Ferrandiz, 2007).

3. La tercera consecuencia tiene, en realidad, una importancia minúscula: si a la pregunta "el concepto de detenido-desaparecido ¿puede aplicarse en España?" hemos de responder en puridad que "no", el hecho de que en la práctica lo estemos haciendo ¿no supone, desde el punto de vista de los rigores teóricos, correr un riesgo demasiado grande pues se puede perder sensibilidad histórica y social?

4. La cuarta consecuencia guarda relación con la fuerza colonizadora del "desaparecido transnacional" cuando moldea nuestra forma de pensar todo otro sujeto nombrado como detenido-desaparecido. Me refiero a una colonización que es estética, histórica y social, que anula diferencias y que encierra al sujeto contenido en el significante "desaparecido" o "afectado por la desaparición forzada" en un modelo cerrado, sin matices, sin variantes no ya solo en lo que atañe a sus causa sino sobre todo en lo que concierne a las expresiones de dolor o resistencia que suceden a la desaparición forzada misma. ${ }^{18}$

\footnotetext{
${ }^{18}$ En relación a este trabajo de colonización estética es digna de análisis —y a mi juicio de crítica — la exposición Desaparecidos, de Gervasio Sánchez, inaugurada en Madrid, Barcelona y León pocas fechas antes de acabar de redactar este trabajo (http://www.
} 
Esta última consecuencia es la que me preocupa $\mathrm{y}$ en buena medida es a pensar en ella que estaba orientado este artículo.

El campo de la memoria y de los derechos humanos está en España en plena constitución y es difícil, si no imposible, indicar por dónde discurrirá en el futuro y qué forma terminará tomando. Lo cierto es que en poco tiempo, cambian sus protagonistas, mutan las alianzas, se trastocan los procesos de construcción de legitimidad... Es un campo precario y móvil. También creativo. Pero tenga la forma que tenga, lo cierto es que existe y que progresivamente se institucionaliza, lo que no es poco si se mira hacia atrás, no más de una década, apenas arrancando el Siglo XXI. Para que tomase forma ese campo, el concepto y la figura del detenido-desaparecido y los procesos de modelización primero, de transnacionalización después y de solidificación en una definición vigorosa, de uso universal, finalmente, han sido claves. Gracias a ello, quienes nunca lo fueron pueden ser ahora llorados (Butler, 2010), pues tienen nombre, pues pueden ser reconocidos con ese nombre. Así es, como en general sucede en la "cultura de los derechos humanos", las distintas formas de víctima que con ella comparecen constituyen marcos de reconocimiento que permiten a sujetos en posición subalterna ser reconocidos, que "produzcan presencia" ${ }^{20}$ y que se sumen de esa manera a una "política cultural de la visibilidad" (Fragoso, 2006: 75).

Ahora bien, como en todo proceso de institucionalización, hay tras él naturalizaciones y cierres categoriales sobre los que conviene estar atentos para evitar hacer del desaparecido y de quienes le sobreviven, esto es, los que habitan el campo de los derechos humanos con la vitola de afectados, sujetos regidos por una sola partitura posible, la de la víctima doliente, encerrados en la retórica del dolor, pura expresión del sufrimiento, sujetos merecedores por eso de atención piadosa: firmes y resistentes sujetan la foto de su deudo, reclaman, y añoran... Hay otras maneras de ser víctima; algunas incluso renuncian al sustantivo. Es cierto que en el contexto de un mundo impregnado de la moral y la justicia humanitarias el desaparecido se ha convertido en una herramienta para el reconocimiento de las víctimas y en una potencial herramienta para hacer justicia. Pero manejada acríticamente, la versión transnacional del concepto puede cancelar la variedad de situaciones que representa. Tal y como parece estar siendo construido, la suya solo es "la verdad de su sufrimiento" (Fassin, 2004: 91). ${ }^{20}$

\section{REFERENCIAS CITADAS}

Agamben, G. (1998). Homo sacer. El poder soberano y la nuda vida. Valencia: Pre-Textos

AgIER, M. (2006). "Le gouvernement humanitaire et la politique des réfugiés", Recueil Alexandries, 10/15. http://www. reseau-terra.eu/article569.html [Acceso el 21 de febrero de 2011]

Agier, M. (2008). Gérer les indésirables. Des camps des réfugiés au gouvernement humanitaire. París: Flammarion BAer, A. (2011). "Los vacíos de Sefarad. La memoria del holocausto en España". Política y Sociedad, 48/3

Bauman, Z. (1997). Legisladores e intérpretes. Sobre la modernidad, la posmodernidad y los intelectuales. Buenos Aires: Universidad Nacional de Quilmes

Butler, J. (2006). Vidas precarias. El poder del duelo y la violencia. Barcelona: Paidós

Butler, J. (2010). Marcos de guerra. Las vidas lloradas. Barcelona: Paidós

Calveiro, P. (2004). Poder y desaparición. Los campos de concentración en Argentina. Buenos Aires: Colihue

\footnotetext{
musac.es/prensa/web16/notas/gsanchez.pdf, acceso el 28 de febrero de 2011).

${ }^{19}$ La idea de "producción de presencia" la toma Rosa Linda Fregoso de Saskia Sassen, 2002, "The Repositioning of Citizenship: Emergent subjects and Spaces for Politics", Berkeley Journal of Sociology, 47.

${ }^{20}$ Pero hay otras verdades posibles, pues los sujetos que tienen vidas extremadamente vulneradas, los sujetos de vidas precarias, en ocasiones hacen de lo que produce su vulnerabilidad (guerra, olvido, duelo permanente... o, por qué no, desaparición forzada de personas) un espacio de vida, y se apropian de la categoría doliente, rechazan la fuente de su vulnerabilidad, la politizan (Agier, 2008), la resignifican (Gatti, 2008). Esta posibilidad, la de hacer de aquello que te sitúa fuera de los marcos en los que está normalmente situado lo humano (Butler, 2010: 43-44) un marco de reconocimiento para la construcción de una comunidad de sentidos a priori imprevistos (Butler, 2006) está pendiente de exploración en el caso del campo de los derechos humanos en España.
} 
Da Silva Catela, L. (2001). No habrá flores en la tumba del pasado. La experiencia de reconstrucción del mundo de los familiares de desaparecidos. La Plata: Ediciones Al Margen

Elias, N. (1988). El proceso de la civilización: investigaciones sociogenéticas y psicogenéticas. México: FCE

Elias, N. (1990). La sociedad de los individuos. Barcelona: Península

Elster, J. (2006). Rendición de cuentas. La justicia transicional en perspectiva histórica. Buenos Aires: Katz

Faber, S., P. SÁnchez León, J. IzQuierdo (2011). "El poder de contar y el paraíso perdido. Polémicas públicas y construcción colectiva de la memoria en España". Política y Sociedad, 48/3

Fassin, D. (2007). "Humanitarianism as a Politics of Live". Public Culture, 19/3

Fassin, D., P. VAsquez (2005). "Humanitarian exception as the rule: The political theology of the 1999 Tragedia in Venezuela". American Ethnologist, 32/3

Fassin, D., R. Rechtman (2007). L'empire du traumatisme. Enquête sur la condition de victime. París: Flammarion

FEIERStein, D. (2011): "Sobre los conceptos y sus consecuencias sobre la identidad: guerra, genocidio y/o terrorismo de Estado". Política y Sociedad, 48/3

FERrÁndiz, F. (2007). “The Return of Civil War Ghosts”. Anthropology Today, 22/3

FERrÁndiz, F. (2010). "De las fosas comunes a los derechos humanos: el descubrimiento de las desapariciones forzadas en la España contemporánea”. Revista de Antropología Social, 19

Fondebrider, L. (1997). Intervención en la mesa "Identidad y antropología forense", en Juventud e Identidad, III Congreso Internacional, (25, 26 y 27 de setiembre de 1997). Buenos Aires: Abuelas de Plaza de Mayo

Foucault, M. (1990). Tecnologías del yo. Barcelona: Paidós

Fregoso, R. L. (2006). “¡Las queremos vivas! Colectividades y cultura de los derechos humanos”, en F. J. Selgas y C. Romero (eds.), El doble filo de la navaja. Violencia y representación. Madrid: Trotta

García Blanco, J. Ma (2011). "Del derecho y su violencia”. Politica y Sociedad, 48/3

Gatti, G. (2007). Identidades débiles. Una propuesta teórica aplicada al estudio de la identidad en el País Vasco. Madrid: CIS

Gatti, G. (2008). El detenido-desaparecido. Narrativas posibles para una catástrofe de la identidad. Montevideo: Trilce

Gatтi, G. (2010a). “Comunidades precarias en los universos sociales del detenido-desaparecido: los 'hijos de', vástagos bastardos traicionando progenies, huérfanos paródicos consumiendo Historia”, en P. de Marinis, G. Gatti, I. Irazuzta (eds.), La comunidad como pretexto. En torno al (re)surgimiento de las solidaridades comunitarias. Barcelona: Anthropos

GAtтi, G. (2010b). "O detido-desaparecido: catástrofe civilizacional, desmoronamento da identidade e da linguagem”. Revista Critica de Ciencias Sociais, 88

Gómez Mango, E. (2006). La desolación. De la barbarie en la sociedad contemporánea. Montevideo: Ediciones de la Banda Oriental

Haraway, D. J. (2004). Testigo_Modesto@Segundo_Milenio.HombreHembra @_Conoce_Oncoratón ${ }^{\circledR}$. Feminismo y tecnociencia. Barcelona: UOC

Hunt, L. (2009). La invención de los derechos humanos. Tusquets: Barcelona

Imaz, E. (2008). Texto sin título en G. Gatti, El detenido-desaparecido. Narrativas posibles para una catástrofe de la identidad. Montevideo: Trilce

JELIN, E. (2003). "Los derechos humanos y la memoria de la violencia política y la represión: la construcción de un campo nuevo en las ciencias sociales". Cuadernos del IDES, 2

JELIN, E. (2011). "Subjetividad y esfera pública: el género y los sentidos de familia en las memorias de la represión”. Política y Sociedad, 48/3

Latour, B. (1985). "Les vues de l'esprit. Une introduction à l'anthropologie des sciences et des techniques". Culture Technique, 14

Latour, B. (2001): La esperanza de Pandora. Ensayos sobre la realidad de los estudios de la ciencia. Barcelona: Gedisa

Latour, B. y É. Hermant (1999). "Esas redes que la razón ignora: laboratorios, bibliotecas, colecciones", en F. J. García Selgas y José B. Monleón (eds.), Retos de la posmodernidad. Ciencias Sociales y Humanas. Madrid: Trotta

Lewkowicz, I. (2002). Sucesos argentinos. Buenos Aires: Paidós

Lewkowicz, I., M. Cantarelli, Grupo Doce (2003). Del fragmento a la situación. Notas sobre la subjetividad contemporánea. Buenos Aires: Altamira 
Maнi, M. (2010). "Judicial Review and Transitional Justice: Reflective Judgement in Three Contexts". Papeles del CEIC, vol. 2010/2, no 60, CEIC (Centro de Estudios sobre la Identidad Colectiva), Universidad del País Vasco, http://www.identidadcolectiva.es/pdf/60.pdf [Acceso el 20 de octubre de 2010]

Mate, R. (2008). Justicia de las víctimas. Terrorismo, memoria, reconciliación. Barcelona: Anthropos

Mate, R. (2009). "Lorca, un desaparecido", EL PAís, 27 de diciembre

Moya, C. (1984). Señas de Leviatán. Madrid: Alianza

Ortega, J. (2010). "Post-teoría y estudios transatlánticos". En I. Rodríguez y J. Martínez (eds.), Estudios transatlánticos poscoloniales. Barcelona: Anthropos

Pradera, J. (2008). "Un mal viaje de ida y vuelta", El País, 3 de diciembre

PRADO, B. (2006). Mala gente que camina. Madrid: Alfaguara

Rama, A. (1998). La ciudad letrada. Montevideo: Arca

Rodríguez Maeso. S. (2011). "Testimonios, discurso experto y comisiones de la verdad: el contexto de la denuncia". Politica y Sociedad, 48/3

Teitel, R. G. (2003). “Transitional Justice Genealogy”. Harvard Human Rights Journal, 16

Wieviorka, M. (2003). "L'émergence des victimes". Sphera publica, 3 